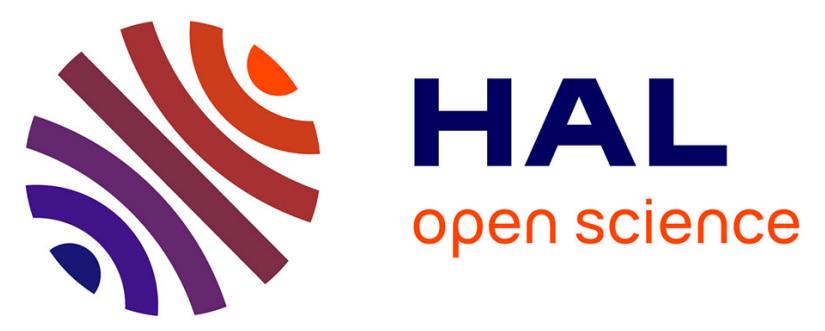

\title{
Editorial for "Association of Type 2 Diabetes Mellitus and Glycemic Control With Intracranial Plaque Characteristics in Patients With Acute Ischemic Stroke"
}

Stanislas Rapacchi, Bénédicte Gaborit

\section{- To cite this version:}

Stanislas Rapacchi, Bénédicte Gaborit. Editorial for "Association of Type 2 Diabetes Mellitus and Glycemic Control With Intracranial Plaque Characteristics in Patients With Acute Ischemic Stroke". Journal of Magnetic Resonance Imaging, 2021, 54 (2), pp.667-668. 10.1002/jmri.27739 . hal03434536

\section{HAL Id: hal-03434536 \\ https://hal-amu.archives-ouvertes.fr/hal-03434536}

Submitted on 18 Nov 2021

HAL is a multi-disciplinary open access archive for the deposit and dissemination of scientific research documents, whether they are published or not. The documents may come from teaching and research institutions in France or abroad, or from public or private research centers.
L'archive ouverte pluridisciplinaire HAL, est destinée au dépôt et à la diffusion de documents scientifiques de niveau recherche, publiés ou non, émanant des établissements d'enseignement et de recherche français ou étrangers, des laboratoires publics ou privés. 
Editorial for "Association of Type 2 Diabetes Mellitus and Glycemic Control With Intracranial Plaque Characteristics in Patients With Acute Ischemic Stroke"

Diabetes has become a major public health concern, with an increasing prevalence of type-2 diabetes mellitus (T2DM) reaching more than $6 \%$ of the world's population in 2017 (1). The burden of diabetes mellitus is rising in parallel with the obesity pandemic and is expected to continue to grow in both highand low-income countries.

In a meta-analysis of Emerging Risk Factors Collaboration, diabetes was estimated to account for $11 \%$ of vascular deaths(2). Indeed, T2DM increases by 2 to 3 fold the risk of coronary artery disease, peripheral artery disease, and cerebrovascular disease (2). Chronic exposure to hyperglycemia is a well-known risk factor for atherosclerosis and early endothelial dysfunction. In response to endothelial injury and inflammation, oxidized lipids from low density lipoproteins (LDL) particles accumulate in the endothelial wall of arteries. In addition to atheroma formation, there is strong evidence of increased platelet adhesion and aggregability in T2DM(3). Previous studies have reported that even short-duration T2DM was associated with increased carotid plaque burden and negative remodeling using MRI(4). Other studies suggest that diabetes could be associated with an increase in carotid plaque vulnerability. However, few studies have analyzed the association between glycemic control and the properties of intracranial atherosclerotic plaques in patients with diabetes mellitus

Three-dimensional MR vessel wall imaging can characterize the atherosclerotic plaques in the major intracranial arteries in a single volume scan and brings new insight in the characterization of intracranial atherosclerosis. Plaque enhancement is an important vulnerable plaque feature that is related to inflammatory activity and increased neovascularity. It has been related to recent ischemic stroke.

In this issue, Li et al. (5) evaluated the association of diabetes and glycemic control with intracranial atherosclerotic plaque characteristics identified by 3D contrast enhanced MR vessel wall imaging in patients after acute ischemic stroke. Thanks to the advent of high-resolution MRI reaching $0.6 \mathrm{~mm}^{3}$ isotropic resolution, they were able to characterize the number of plaques detected, and their level of enhancement, the degree of luminal stenosis, plaques' length, enhancement ratio and the presence of hemorrhage. Patients were separated in non T2DM $(n=99)$ and well $(n=44)$ or poorly controlled T2D $(n=82)$ depending on their HbA1c at the time of admission. This study interestingly reported that T2DM was associated with an increased number of intracranial plaques and that $\mathrm{HbA1c}$ was an independent factor for higher enhancement ratio of culprit plaques. This finding suggested that glycemic control status might have a greater impact than the history of diabetes on intracranial atherosclerotic disease. However, the absence of diabetes duration evaluation and the lack of difference regarding fasting blood glucose and HbA1c levels between the non-T2DM group and the well-controlled T2DM groups questions about the reliability of one $\mathrm{HbA1c}$ assessment to reflect cumulative glycemic exposure. Furthermore, elevated $\mathrm{HbA} 1 \mathrm{c}$ at the time of admission might also be associated with less controlled other risk factors or poor general condition of the patient.

However, these results align very well with the study of Jiao et al.(6) who retrospectively looked for intracranial plaque MRI features in cerebrovascular patients, including stroke patients. Both employed contrast-enhanced vessel-wall MRI in acute patients, and both studies revealed a significant relationship between plaque enhancement and poor glycemic control. This reinforces the hypothesis that glycemic 
control could play an important role in the development of vulnerable intracranial atherosclerosis. Interestingly, Li et al. reported the number of plaques and isolated the culprit plaque for a separate analysis, while Jiao et al. reported only the features of the culprit plaque. Thus, only Li et al. observed that the number of plaques was significantly higher in T2DM patients. However, the culprit plaque characteristics, such as length and stenosis, differed significantly between the two studies, with, for instance, a reported mean plaque length of $7.9 \mathrm{~mm}$ from Li et al. and $5.5 \mathrm{~mm}$ from Jiao et al. It can be hypothesized that such gap arises from measurement methodology rather than factual differences. Eventually, these variations in measurements might explain the discrepancies of Jiao et al. reporting significant correlations between plaque length, plaque stenosis and glycemic control when Li et al. did not.

Finally, comparing these two studies highlights the need for standardization of measurement, and subsequent reporting, to fully appreciate novel imaging-based biomarkers and highlights the contribution of novel non-invasive imaging modalities such as three-dimensional MR vessel wall imaging in the pathogenesis of diabetic atherothrombosis.

\section{References}

1. Khan MAB, Hashim MJ, King JK, Govender RD, Mustafa H, Al Kaabi J: Epidemiology of Type 2 Diabetes

- Global Burden of Disease and Forecasted Trends. J Epidemiol Glob Health 2020; 10:107-111.

2. Emerging Risk Factors Collaboration, Sarwar N, Gao P, et al.: Diabetes mellitus, fasting blood glucose concentration, and risk of vascular disease: a collaborative meta-analysis of 102 prospective studies. Lancet 2010; 375:2215-2222.

3. Gaborit B, Frère C, Cuisset T, Alessi M-C, Dutour A: Enhanced post-clopidogrel platelet reactivity in diabetic patients is independently related to plasma fibrinogen level but not to glycemic control. $J$ Thromb Haemost 2009; 7:1939-1941.

4. Laugesen E, Høyem P, Thrysoe S, et al.: Negative Carotid Artery Remodeling in Early Type 2 Diabetes Mellitus and Increased Carotid Plaque Vulnerability in Obesity as Assessed by Magnetic Resonance Imaging. J Am Heart Assoc 2018; 7:e008677.

5. Li X, Sun B, Wang L, et al.: Association of Type 2 Diabetes Mellitus and Glycemic Control With Intracranial Plaque Characteristics in Patients With Acute Ischemic Stroke. Journal of Magnetic Resonance Imaging 2021; n/a(n/a).

6. Jiao S, Huang J, Chen Y, et al.: Impacts of Glycemic Control on Intracranial Plaque in Patients with Type 2 Diabetes Mellitus: A Vessel Wall MRI Study. American Journal of Neuroradiology 2021; 42:75-81. 